\title{
BRONCHOSCOPY IN RANGPUR MEDICAL COLLEGE HOSPITAL - OUR EXPERIENCE OF 02 YEARS
}

\author{
A.K.M. SHAHEDUZZAMAN ${ }^{1}$, DEVENDRA NATH SARKAR ${ }^{2}$, MD.ISMAIL HOSSAIN $^{3}$, MD. REHAN HABIB $^{4}$, MD. $^{2}$ \\ MAHFUZER RAHMAN ${ }^{5}$, SHAH MD. SARWER JAHAN ${ }^{5}$, MD. ZAKIR HOSSAIN 6
}

\begin{abstract}
Background: Bronchoscopy can play a major role in both diagnosis and treatment. Diagnostic bronchoscopy is a useful tool for the diagnosis of pulmonary lesions particularly bronchogenic carcinoma and pulmonary tuberculosis
\end{abstract}

Aim: To find out the role of fibre-optic bronchoscopy in the diagnosis of pulmonary diseases.

Methods: This observational study was conducted in the Indoor patient, Department of Medicine in Rangpur Medical College Hospital. Of all patients aged 18 years and above Undiagnosed pulmonary lesion in the medical wards between October 2012 to October 2014.

\begin{abstract}
Results: Out of 256 cases, mean age $\pm S D$ was 61.01( \pm 11.51$)$, minimum age was 23 and maximum age was 86 years. Majority $84 \%$ were male and $16 \%$ were female. Most of the respondent were smoker whereas (82\%). Most common presenting complains were cough, dyspnoea, haemoptysis and fever 83\%, 59.3\%,53\% and 36\% respectively. General Physical examination findings, 97\% were anamia and clubbing were $41 \%$ and cyanosis $02 \%$. Respiratory system examination findings, $54 \%$ were features suggestive of complete collapse, $15 \%$ features suggestive of consolidation and $31 \%$ normal chest findings. Chest $x$-ray findings of the study population, $25.8 \%$ were dense homogenous opacity involving right or left lung field, 17.9\% were complete collapse of affected lungs , 5.5\% were right middle lobe collapse, 4.3\% Unilateral hilar lymphadenopathy, 7.03\% were elevation of hemidiaphragm of affected site and $7.03 \%$ were pleural effusion. $6.6 \%$ patient had normal CxR. In present study shows bronchoscopic findings in patients studied, Vocal cord paralysis were 9.3\%, Right main bronchus were 15.6\%, Right upper lobe bronchus were $7.03 \%$, Right middle lobe bronchus were 7.8\%, Right lower lobe bronchus were 9.8\%, Left main bronchus were 14\%, Left upper lobe $4.3 \%$, Left lingular were $1.9 \%$ and Left lower lobe bronchus were 9.3\%.In this study shows histologhical findings majority $18 \%$ were squamaus cell carcinoma,8.2\% were small cell carcinoma, 2.3\% were adeno carcinoma, 6.6\% infiltration of Inflammatory cell and granuloma $1.2 \%$.
\end{abstract}

Conclusion: In this study male are predominant. Most of the respondent was smoker. Most common presenting complains were cough, haemoptysis, fever and chest pain. Most of general physical examination findings were anamia and clubbing. Respiratory system examination findings were features suggestive of complete collapse, features suggestive of consolidation and normal chest findings. chest $x$-ray findings of the study population were complete collapse of affected lungs, rtight middle lobe collapse, Dense homogenous opacity involving right or left lung field, Unilateral hilar lymphadenopathy. Bronchoscopic findings were vocal cord paralysis, right main bronchus, right upper lobe bronchus, right middle lobe bronchus, right lower lobe bronchus, left main bronchus, left lingual and left lower lobe bronchus. Histologhical findings majority were squamaus cell carcinoma. Most of the patient poorly differentiated carcinoma among the study subjects.

Received: 10 September 2015

Accepted: 3 November 2015

1. Assistant Professor, Department of Medicine, Rangpur Medical College \& Hospital, Rangpur.

2. Professor, Department of Medicine, Rangpur Medical College \& Hospital, Rangpur

3. OSD, Directorate General of Health Services, Deputed in BSMMU, Dhaka,

4. Registrar, Department of Medicine, Rangpur Medical College \& Hospital, Rangpur.

5. Associate Professor, Department of Medicine, Dhaka Medical College \& Hospital, Dhaka.

6. Professor and Head, Department of Medicine, Rangpur Medical College, Rangur.

Correspondence to: Dr. Md. Ismail Hossain, OSD, Directorate General of Health Services, Deputed in BSMMU, Dhaka, Bangladesh. email-drrusse127@gmail.com.

Bangladesh J Medicine 2016; $27: 16-21$ 


\section{Introduction}

Diagnostic bronchoscopy is a useful tool for the diagnosis of pulmonary lesions particularly bronchogenic carcinoma and pulmonary tuberculosis. Fibreoptic bronchoscopy can play a major role in both diagnosis and treatment. ${ }^{1}$ Flexible bronchoscopy is a safe diagnostic and therapeutic procedure. In the absence of risk factors, complications such as bleeding are rare. ${ }^{2}$ The diagnostic yield of fiberoptic bronchoscopy (FOB) is high, though it depends on the indication and the technique used. ${ }^{3}$ Performance of outpatient fiberoptic bronchoscopy has resulted in facilitation of health care services and lower costs. ${ }^{4}$ Ikeda designed a flexible FOB in 1968, and emphasized that direct vision was better than the rigid bronchoscope in the diagnosis of bronchogenic carcinoma. ${ }^{5}$ After the discovery of this instrument there was a revolution in the diagnosis and management of respiratory diseases. FOB is commonly done on patients to establish a diagnosis. There are numerous therapeutic uses also. The diagnostic yield of FOB and biopsy of an endobronchially visible carcinoma is above $90 \% .{ }^{6}$ FOB has been well established as a useful diagnostic procedure in evaluating hemoptysis. Hemoptysis is one of the most frequent indications for FOB, and it accounts for 10 to 30 percent of bronchoscopic procedures in major medical centers of patients with normal findings on chest roentgenograms. ${ }^{7}$

In the clinical evaluation of pulmonary disease, fiberoptic bronchosopy is a crucial tool in the diagnosis of a variety of chest diseases. Though often instrumental in the diagnosis of a variety of neoplastic, inflammatory, and infectious diseases, fiberoptic bronchscopy (FOB) can have important limitations. Patients with serious underlying cardiac and respiratory diseases may not be fit to undergo the procedure. It may not be tolerated in the young, in the critically ill, or in patients with bleeding disorders and uncooperative patients. In patients with significant airway stenoses, stricture and obstruction, bronchoscopic evaluation of the airway distal to areas is technically difficult and may compromise patient oxygenation significantly. Equally important, the evaluation of extraluminal pathology is significantly limited in fiberoptic bronchoscopy. ${ }^{8-10}$

Fiberoptic bronchoscopy (FOB) is widely used in intensive care unit practice for diagnostic evaluation and for toilet of the tracheobronchial tree. Fiberoptic bronchoscopy (FOB) is an important entry in the armamentarium of procedures listed in management of respiratory problems. It is a simple and a safe procedure. FBS has a great scope for diagnosis as well as therapy of various pulmonary disorders. Today there are two major types of bronchoscopes i.e. the rigid Jackson bronchoscope and the flexible fiberoptic bronchoscope (FBS). The flexible bronchoscope has continued to gain utility primarily as a diagnostic tool. However, recently it has also become a popular modality for many therapeutic purposes like removal of mucous plugs \& small foreign bodies. The advantages offered by this intervention are that it can be done by trained professionals $\&$ requires minimal skill training. Also the rapid \& easy repeatability of the test offers a big advantage over the other conventional modalities like biopsy, thoracotomy, aspiration etc. BAL fluid cultures has the potential to provide sensitive $\&$ specific means to diagnose pneumonia in ventilated patients $\&$ may provide relevant information about the causative pathogens. The lack of absolute contraindications \& relative safety of this intervention scores over other modalities of treatment.

\section{Materials and Methods}

This hospital based observational study was conducted in the Indoor patient, Department of Medicine in Rangpur Medical College Hospital. Of all patients aged 18 years and above in 256 patients with undiagnosed pulmonary lesion in the medical wards between October 2012 to October 2014 was the study sample. Respiratory diseases having definite indication i.e undiagnosed central pulmonary lesion, collapse of lung, unexplained haemoptysis, unresolved lung abscess, participants who gave written informed consent and willing to comply with the study procedure, was included. A chest xray (P-A) was the prerequisite before enrollment in the study. Bronchoscopy was done by trained respiratory physician in the department of Medicine with standard precaution and procedure and the report was given by same respiratory specialist. Other routine and specific investigations were done according to the patients status and clinical suspicion. All the standard procedure of good clinical practice were done during investigations. Semi structured questionnaire was used in 256 study participants during enrollment and the patients were followed up during hospital stay.

\section{Statistical Analysis}

Data was processed and analyzed using SPSS (Statistical Package for Social Sciences) software. Data processed on categorical scale was presented as frequency and percentage. While the data presented on continuous scale it was presented as mean standard deviation and analyzed with the help of student't' test. The summarized data was then presented in the table and chart. 


\section{Results}

Table-I

Age distribution

\begin{tabular}{lcc}
\hline Years & Frequency & Percent \\
\hline $21-30$ & 12 & 4.6 \\
$31-40$ & 10 & 3.9 \\
$41-50$ & 41 & 16 \\
$51-60$ & 75 & 29.3 \\
$61-70$ & 71 & 27.7 \\
$>70$ & 47 & 18.3 \\
\hline Total & 256 & 100 \\
\hline
\end{tabular}

Minimum age was 23 and maximum age was 86 years, Maximum age group was 51 to 70 years.

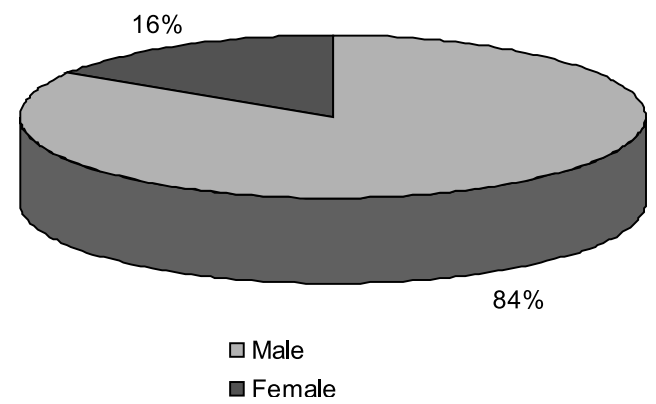

Fig.-1: Shows majority $84 \%$ were male and $16 \%$ were female.

Table-II

Sex distribution

\begin{tabular}{lcc}
\hline & Frequency & Percent \\
\hline Male & 215 & 84 \\
Female & 41 & 16 \\
\hline Total & 256 & 100 \\
\hline
\end{tabular}

Table II shows majority $84 \%$ were male and $16 \%$ were female.

Table-III

Occupational distribution

\begin{tabular}{lcc}
\hline & Frequency & Percent \\
\hline Housewife & 30 & 11.7 \\
Farmer & 110 & 43 \\
Business & 45 & 17.5 \\
Service & 65 & 25.4 \\
Others & 06 & 2.4 \\
\hline Total & 256 & 100 \\
\hline
\end{tabular}

Table-III shows majority $43 \%$ were farmer, followed by $25.4 \%$ were service holder, $17.5 \%$ were businessman and $11.7 \%$ were housewife.

Table-IV

Presenting complaints

\begin{tabular}{lcc}
\hline & Frequency & Percent \\
\hline Cough & 213 & 83 \\
Haemoptysis & 136 & 53 \\
Dyspnoea & 152 & 59.3 \\
Fever & 92 & 36 \\
Chest pain & 69 & 27 \\
Change of voice & 21 & 8.2 \\
\hline
\end{tabular}

Table-V

Smoking history

\begin{tabular}{lcc}
\hline & Frequency & Percent \\
\hline Smoker & 210 & 82 \\
Non Smoker & 46 & 18 \\
\hline Total & 256 & 100 \\
\hline
\end{tabular}

Table $\mathrm{V}$ shows most of the respondent were smoker whereas $(82 \%)$ and $18 \%$ were nonsmoker.

Table-VI

CXR findings of the patients

\begin{tabular}{lcc}
\hline & Frequency & Percent \\
\hline Complete collapse of affected lung & 46 & 17.9 \\
Rt middle lobe collapse & 14 & 5.5 \\
Rt lower lobe collapse & 18 & 7.03 \\
Lt lower lobe collapse & 19 & 7.4 \\
Pulmonary opacity & 66 & 25.8 \\
Unilateral hilar lymphadenopathy & 11 & 4.3 \\
Elevated hemidiaphragm & 18 & 7.03 \\
Pleural effusion & 18 & 7.03 \\
Lung abscess & 09 & 3.5 \\
Normal CxR & 17 & 6.6 \\
Others & 20 & 7.8 \\
\hline Total & 256 & 100 \\
\hline
\end{tabular}

Table-VI shows maximum CxR findings were pulmonary opacity $(25.8 \%)$. 
Table-VII

Bronchoscopic findings

\begin{tabular}{lcc}
\hline & Frequency & Percent \\
\hline Vocal cord paralysis & 24 & 9.3 \\
Rt main bronchus & 40 & 15.6 \\
Rt upper lobe bronchus & 18 & 7.03 \\
Rt middle lobe bronchus & 20 & 7.8 \\
Rt lower lobe bronchus & 25 & 9.8 \\
Lt main bronchus & 36 & 14 \\
Lt upper lobe bronchus & 11 & 4.3 \\
Lt lingular lobe bronchus & 05 & 1.9 \\
Lt lower lobe bronchus & 24 & 9.3 \\
Trachea & 02 & .78 \\
Supraglottic & 01 & .39 \\
Normal Tracheobronchial tree & 65 & 25.4 \\
\hline Total & 256 & \\
\hline
\end{tabular}

Table VII shows maximum bronchoscopic findings were normal $(25.4 \%)$ followed by lesion in right upper lobe bronchus (15.6\%).

Table-VIII

Histoligical findings

\begin{tabular}{lcc}
\hline & Frequency & Percent \\
\hline Squamous cell carcinoma & 46 & 18 \\
Small cell carcinoma & 21 & 8.2 \\
Adenocarcinoma & 06 & 2.3 \\
Granuloma & 03 & 1.2 \\
Inflammation & 17 & 6.6 \\
Inadequate tissue & 03 & 1.2 \\
Report N/A & 11 & 4.3 \\
\hline Total & 107 & 100 \\
\hline
\end{tabular}

Table-VIII shows maximum histological findings were squamous cell carcinoma (18\%) and minimum findings were granuloma $(1.2 \%)$.

\section{Discussion}

Diagnostic bronchoscopy is a useful tool for the diagnosis of pulmonary lesions particularly bronchogenic carcinoma and pulmonary tuberculosis. Bronchoscopy can play a major role in both diagnosis and treatment. The aim of this study is to find out the utility of fibre-optic bronchoscope in the evaluation of undiagnosed pulmonary diseases admitted at medicine ward in Rangpur Medical college Hospital.

In this study mean age $\pm \mathrm{SD}$ was $61.01( \pm 11.51)$, minimum age was 23 and maximum age was 86 years, Maximum age group was 51 to 70 years $57 \%$. Majority $84 \%$ were male and $16 \%$ were female. In a study conducted by Flieter et al the mean age was 61 years. Naidich et al in his study found the mean age to be 52 years. In a study by Flieter et $\mathrm{al}^{11}$ showed a male predominance. Naidich et $\mathrm{al}^{12}$ in their study also showed a male redominance. 261 (75.2\%) males and $86(24.8 \%)$ females with a male to female ratio of 303:100. ${ }^{13}$ The median age at diagnosis was 63 years among males (range 0-94 years) and 61 years among females (range 17-90 years). ${ }^{14,15}$

In this study most of the respondent were smoker whereas (82\%) and $18 \%$ were nonsmoker. The preponderance of males is probably related to their smoking habit, smoking being rare in females in our country, as well as their greater exposure to environmental pollutants. Tobacco use is by far the most important risk factor in the development of lung cancer. In 1979, the US Surgeon General estimated that $90 \%$ of lung cancer deaths in males and $79 \%$ in females are due to cigarette smoking. ${ }^{16}$ Smoking more than 20 cigarettes a day has been shown to confer a risk of between 15-25 fold relative to nonsmokers. ${ }^{17,18}$

In present study most common presenting complains were cough, dyspnoea, haemoptysis and fever $83 \%$, $59.3 \%, 53 \%$ and $36 \%$ respectively. Compared with Khara NV, et $\mathrm{al}^{19}$ study, the most common clinical feature in the study participants was cough (91.7\%) followed by dyspnea (66.8\%), fever $61.9 \%$ and chest pain (38.8\%).

The most common presenting symptom was cough (44.6\%) followed by fever (32.8\%), dyspnea (27.6\%), chest pain $(24.8 \%)$ and hemoptysis $(22.3 \%)$. In our study the most common presenting symptom, similar to the previous studies 20,21 was cough (44.6\%). A study of lung cancer in Saudi Arabia reports a higher incidence of symptoms apparently due to the cases being more advanced ${ }^{22}$. Cough may be due to local growth in the main airway or it may be a feature of large airway obstruction causing post obstructive pneumonia. Bovine cough was seen in our patients with lung cancer infiltrating recurrent laryngeal nerve. ${ }^{23}$

In this study chest $x$-ray findings of the study population, $25.8 \%$ were dense homogenous opacity involving right or left lung field, $17.9 \%$ were complete collapse of affected lungs, 5.5\% were rtight middle lobe collapse, $4.3 \%$ Unilateral hilar lymphadenopathy, 
$7.03 \%$ were elevation of hemidiaphragm of affected site and $7.03 \%$ were pleural effusion. $6.6 \%$ patient had normal CxR.

Compared with Fasihuddin S et al study showed, chest $\mathrm{X}$-rays and $\mathrm{CT}$ scan had been reviewed and reported by a consultant radiologist in our hospital. 385 patients $(96.5 \%)$ had abnormality on plain chest $\mathrm{x}$ ray or CT scan or both, while 14 patients (3.5\%) had normal X-ray chest and CT scan. Radiologically, lesions were in the right lung in $211(52.9 \%)$ cases studied - 115(28.8\%) in the right upper lobe, $54(13.5 \%)$ in the right middle lobe and $44(11.0 \%)$ in the right lower lobe; in the left lung in $121(30.3 \%)$ patients $52(13.0 \%)$ in the left upper lobe, $31(7.8 \%)$ in the lingula and $38(9.5 \%)$ in the left lower lobe. In $53(13.3 \%)$ patients radiological lesions were either bilateral or involving more than one lobe. ${ }^{24}$

X-ray chest and CT scan play a pivotal role in the diagnosis of both bronchogenic carcinoma and pulmonary tuberculosis. Of the cases in Fasihuddin S et al study, almost all (93.4\%) had abnormality on chest radiography. Lesions were more common in the right lung compared to the left in our study $(53 \%$ versus $30.5 \%$ ). Right upper lobe was the most commonly involved lobe (29\%) and multilobar involvement was present in $13.5 \%$. It is accepted knowledge that upper lobes are more susceptible to both lung cancer and pulmonary tuberculosis; this may be related to the fact that the upper lobes are less vascular, better aerated and more affected by smoking. CT scan is more sensitive then Chest $\mathrm{x}$-ray in the diagnosis of pulmonary lesions.

Fibreoptic bronchoscopy showed lesion more commonly in the right lung compared to the left $40 \%$ versus $29 \%$ ). The lesion was obviously inoperable on bronchoscopy in $22 \%$, the reasons being vocal cord involvement, tracheal mass or stenosis and widening of carina. ${ }^{24}$ In present study shows bronchoscopic findings in patients studied, Vocal cord paralysis were 9.3\%, Right main bronchus were $15.6 \%$, Right upper lobe bronchus were $7.03 \%$, Right middle lobe bronchus were $7.8 \%$, Right lower lobe bronchus were $9.8 \%$, Left main bronchus were 14\%, Left upper lobe $4.3 \%$, Left lingular were $1.9 \%$ and Left lower lobe bronchus were $9.3 \%$.

In a study showed $83(84.6 \%)$ involvement of trachea, main stem bronchi and lobar bronchi and 15(15.4\%) involvement of segmental bronchi on virtual bronchoscopy. Naidich et $\mathrm{al}^{17}$ in their study showed involvement of $34(69.4 \%)$ cases in the trachea, main stem bronchus, lobar bronchi and 15(30.6\%) involvement of segmental bronchi on fibreoptic bronchoscopy. Narrowing in $64(72.72 \%)$ of cases, occlusion in $14(15.9 \%)$ of cases, mass in $9(9.09 \%)$ of cases and distortions in $2(2.27 \%)$ of cases.

In this study shows histologhical findings majority $18 \%$ were squamaus cell carcinoma , $8.2 \%$ were small cell carcinoma, $2.3 \%$ were adeno carcinoma, $6.6 \%$ infiltration of Inflammatory cell and granuloma 1.2\%. Bronchial biopsy and washing confirmed the diagnosis of bronchial carcinoma in $16 \%(n=64)$ of patients in Fasihuddin S study. ${ }^{24}$ In Fasihuddin S et al. ${ }^{24}$ study small cell carcinoma, squamous cell carcinoma and adenocarcinoma have almost similar incidences with large cell carcinoma relatively uncommon. Cancer incidence report, Saudi Arabia 1999-2000 showed a lower incidence of small cell carcinoma (10\%), with adenocarcinoma (30\%) and squamous cell carcinoma $(27 \%)$ being more common. A recent study of lung cancer at a university hospital in Saudi Arabia showed a high incidence of squamous cell carcinoma (52\%). ${ }^{38}$ In USA, adenocarcinoma followed by squamous cell carcinoma are the most common histologic subtypes of lung cancer. ${ }^{25}$

\section{Acknowledgement}

We are grateful to Dr. Md.Golam Mostofa, Director of Rangpur Medical College Hospital for allowing us to collect the data for this study while we were working in medicine department of this hospital. We also like to thank all the Nurses caring for the hepatitis patients and to all the staffs working in this department for their cordial helduring this study.

\section{References}

1. Fasihuddin S, Mashlah-A, Alkaffas E and Tauheed H, Eight Year Audit of Fibreoptic Bronchoscopies Performed at King Abdul Aziz Hospital, Pakistan Journal of Chest Medicine, 2012 July-Sept; 18(3): 9-16

2. Pue CA, Eric R. Pacht ER. Complications of Fibreoptic Bronchoscopy at a University Hospital. Chest 1995; 107: 430-32

3. Alzeer AH, Al-Otair HA, Al-Hajjaj MS. Yield and complications of flexible fiberoptic bronchoscopy in a teaching hospital, Saudi Med J 2008; 29(1): 55-59.

4. Khan MA. Fibreoptic bronchoscopy as an outpatient procedure. Arch Intern Med 1983; 143: 25-26.

5. Ikeda S: Flexible-bronchofiberscope. Annals of Oto Rhino Laryngology, 1970;79:916-923

6. Popovich J Jr, Kvale PA, Eichenhorn MS, et al. Diagnostic accuracy of multiple biopsies from flexible fiberoptic bronchoscopy: a comparison of central versus peripheral carcinoma. Am Rev Respir Dis $1982 ; 125: 521-23$ 
7. Jackson CV, Savage PJ, Quinn DL. Role of fiberoptic bronchoscopy in patients with hemoptysis and a normal chest roentgenogram. Chest 1985; 87 : $142-44$

8. Hu H, He HD, Foley WD, et al. Four multidetectorrow helical CT: image quality and volume coverage speed. Radiology 2000; 215:55-62.

9. Klingenbeck-Regn K, Schaller S, Flohr T, et al.Subsecond multi-slice computed tomography: basics and applications. Eur J Radiology 1999; 31:110-124.

10. Rigauts H. One year experience with the multislice helical CT. J Belge Radiology 1998; 82:273-276.

11. Fleiter T, Merkle EM, Aschoff AJ, et al. Comparison of real time virtual and fibreoptic bronchoscopy in patients with bronchial carcinoma: oppurtunities and limitations. AJR Am J Roengenol 1997; 169: 159-163.

12. Naidich DP, Lee JJ, Garav SM, McCaauley DI, Aranda $\mathrm{CP}$, and Boyd AD. Comparison of CT and fiberoptic bronchoscopy in the evaluation of bronchial disease. American Journal of Roentgenology; 148(1): 1-7.

13. Cancer Incidence Report,Saudi Arabia 2005. National Cancer Registry. Ministry of Health. Kingdom of Saudi Arabia; 2005:46

14. Sarkar,S.K., Sharma GS, Gupta PR, Sharma, R.K. Fiberoptic bronchoscopy in the diagnosis of pulmonary tuberculosis.Tubercle 1980,61: 97-99.

15. Uddenfeldt,M.,Lundgren,R.:Fibreoptic bronchoscopy in the diagnosis of pulmonary tuberculosis. Tubercle 1981,62:197-199.

16. Cancer Incidence Report, Saudi Arabia 1999-2000. National Cancer Registry.Ministry of Health. Kingdom of Saudi Arabia; 2004:1-122.
17. Hammond EC.Smoking in relation to the death rates of one million men and women.Natl Cancer Inst Monogr 1966;19: 127-204

18. Doll R, Peto R, Wheatly K, Gray R, Sutherland I. Mortality in relation to smoking: 40 years observation on male british doctors. Br Med J 1994; 309: 901-11

19. Khara NV, Kshatriya RM, Vala DH, Prajapati DN, Paliwal RP, Satish N Patel5, diagnostic yield of fiberoptic bronchoscopy (fob) in three common lung conditions at a Rural teaching hospital, National Journal of Medical Research,2013;3: (4):392-95.

20. Beckles MA, Spiro SG, Colice GL, Rudd RM. Initial evaluation of the patient with lung cancer. Symptoms, sign, laboratory tests, and paraneoplastic syndromes. Chest 2003;123:97S-104.

21. Al Jahdali A. Evaluation of the patient with lung cancer. Ann Thorac Med - Suppl Lung Can Guidelines 2008;3:74S-8.

22. Lung cancer at a university hospital in Saudiarabia.A four year prospective study of clinical, pathological, radiological, bronchoscopic, and biochemical parameters. Ann Thorac Med 2010; 5: 30-36

23. Croften and Douglas's Respiratory Diseases:2, Anthony Seaton, Douglas Seaton, A.Gordon Leitch. 2000: 41:1086

24. Fasihuddin S, Mashlah-A, Alkaffas E and Tauheed H. Eight Year Audit of Fibreoptic Bronchoscopies Performed at King Abdul Aziz Hospital, Makkah, Saudiarabia Pakistan Journal of Chest Medicine, 2012 July-Sept; 18(3): 9-16

25. Kramer H, Groen HJ. Current Concepts in the mediastinal lymph node staging of nonsmall cell lung cancer. Ann Surg 2003;238:180-8. 